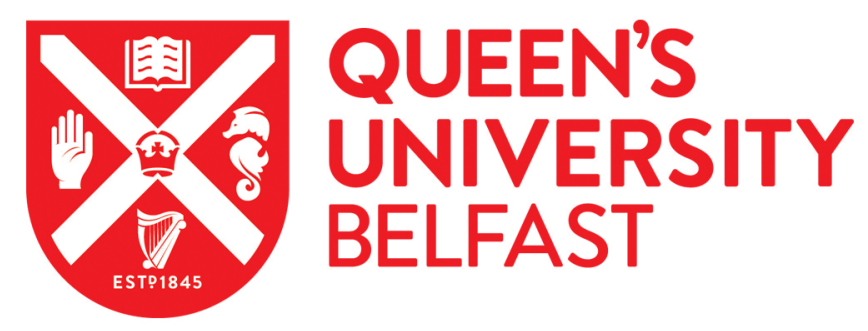

\title{
The effect of porous structure on the cell proliferation, tissue ingrowth and angiogenic properties of poly(glycerol sebacate urethane) scaffolds
}

Samourides, A., Browning, L., Hearnden, V., \& Chen, B. (2020). The effect of porous structure on the cell proliferation, tissue ingrowth and angiogenic properties of poly(glycerol sebacate urethane) scaffolds. Materials Science and Engineering C, 108, [110384]. https://doi.org/10.1016/j.msec.2019.110384

Published in:

Materials Science and Engineering $C$

Document Version:

Peer reviewed version

Queen's University Belfast - Research Portal:

Link to publication record in Queen's University Belfast Research Portal

Publisher rights

Copyright 2019 Elsevier.

This manuscript is distributed under a Creative Commons Attribution-NonCommercial-NoDerivs License

(https://creativecommons.org/licenses/by-nc-nd/4.0/), which permits distribution and reproduction for non-commercial purposes, provided the author and source are cited.

\section{General rights}

Copyright for the publications made accessible via the Queen's University Belfast Research Portal is retained by the author(s) and / or other copyright owners and it is a condition of accessing these publications that users recognise and abide by the legal requirements associated with these rights.

\section{Take down policy}

The Research Portal is Queen's institutional repository that provides access to Queen's research output. Every effort has been made to ensure that content in the Research Portal does not infringe any person's rights, or applicable UK laws. If you discover content in the

Research Portal that you believe breaches copyright or violates any law, please contact openaccess@qub.ac.uk. 
The effect of porous structure on the cell proliferation, tissue ingrowth and angiogenic properties of poly(glycerol sebacate urethane) scaffolds

\author{
Andreas Samourides ${ }^{1}$, Lauren Browning ${ }^{1}$, Vanessa Hearnden ${ }^{1 *}$, Biqiong Chen $^{1,2^{*} \dagger}$ \\ ${ }^{1}$ Department of Materials Science and Engineering, University of Sheffield, Kroto Research Institute, Broad Lane, \\ Sheffield S3 7HQ, United Kingdom \\ ${ }^{2 \dagger}$ School of Mechanical and Aerospace Engineering, Queen’s University Belfast, Stranmillis Road, Belfast BT9 \\ 5AH, United Kingdom \\ *Corresponding authors: b.chen@qub.ac.uk (BC); v.hearnden@ sheffield.ac.uk (VH). \\ ${ }^{\dagger}$ Present address
}

\begin{abstract}
Novel, porous, biodegradable biomaterials which support tissue integration and angiogenesis and which have elastomeric properties are needed to repair and replace soft tissues in dynamic environments. In this study poly(glycerol sebacate urethane) (PGSU) scaffolds with different porous structures were fabricated using freeze-drying by varying the polymer concentration of the freeze-drying solution, during which the polymer was further crosslinked. The effect of the porous structure on the physical properties, cell proliferation, tissue ingrowth and angiogenic properties was investigated. By increasing the polymer concentration in the freeze-drying solution from $5 \mathrm{w} / \mathrm{v} \%$ to $10 \mathrm{w} / \mathrm{v} \%$ and $15 \mathrm{w} / \mathrm{v} \%$, the porosity and pore size of the scaffold decreased, resulting in porosities ranging between $88-96 \%$ and pore sizes $6.4-28.2 \mu \mathrm{m}$. The mechanical properties increased with the polymer concentration, with ultimate tensile strength and Young's modulus between $0.05-0.86 \mathrm{MPa}$ and $0.05-0.65 \mathrm{MPa}$ respectively and negligible loss of tensile strength after 100 cycles of loading. Enzymatic degradation over 28 days demonstrated linear degradation kinetics with mass loss between $19.1-52.3 \%$. All PGSU scaffolds provided a viable environment for cell attachment, in which cell metabolic activity increased over time indicating cell proliferation. The cells adhered to PGSU scaffolds produced
\end{abstract}


and deposited high quantities of collagen, reaching $7.5 \%$ of the sample's dry mass after 14 days culture for the scaffold with the highest porosity. Additionally, the scaffolds with the polymer concentration of $5 \mathrm{w} / \mathrm{v} \%$ implanted onto the chick chorioallantoic membrane supported rapid tissue ingrowth and new blood vessel formation within the porous scaffold. These results demonstrate that PGSU scaffolds have potential for use in many areas of soft tissue engineering.

\section{Keywords}

Poly(glycerol sebacate urethane); Freeze-drying; Tissue scaffold, Collagen production; Angiogenesis; Soft tissue engineering

\section{Introduction}

Tissue engineering (TE) is a multidisciplinary field, aiming to regenerate or replace damaged and malfunctioned tissues or organs [1]. The success of tissue engineered products relies on developing scaffolds which support cell survival and integration into host tissues. Scaffolds with high porosity and highly interconnected pore structures are desirable as they mimic naturally occurring tissue structures, allow cell-cell communication as well as facilitating gas and nutrient exchange for cell proliferation [2]. Following implantation, the degradation of scaffolds and simultaneous substitution with cell derived matrix proteins enable long term tissue replacement [3]. Therefore the development of new biomaterials which are biocompatible, biodegradable and can be fabricated into 3D structures with defined porous structure and mechanical properties are needed [4]. Furthermore, ensuring new blood vessels populate scaffolds rapidly after implantation, in order for cells to receive an adequate supply of gas and nutrients, remains a great challenge in TE [5]. 
The most common synthetic biodegradable biomaterials developed for TE scaffolds are poly(lactic acid) [6], poly(lactic-co-glycolic acid) (PLGA) [7], poly( $\varepsilon$-caprolactone) (PCL) [8] and poly(ethylene glycol) (PEG) [9]. One of the shortcomings of these polymers are that their mechanical properties do not match the elastic properties of extracellular matrix in many soft tissues, and they undergo plastic deformation and fail when exposed to cyclic loading [10]. To overcome these disadvantages, poly(glycerol sebacate) (PGS) was developed which is a biocompatible and biodegradable elastomer synthesised by polycondensation of glycerol and sebacic acid [11]. PGS is capable of sustaining a load and recovering from mechanical deformation allowing it to be used for soft tissues that are in dynamic environments [12]. In addition, its mechanical properties and degradation rate can be tailored by controlling the molecular weight of the PGS prepolymer (pre-PGS) and curing conditions, supporting its development as a biomaterial for soft TE applications [13, 14]. In previous studies, PGS was reported to have an ultimate tensile strength (UTS) between $0.23-0.79 \mathrm{MPa}$, Young's modulus (E) $0.04-2.12 \mathrm{MPa}$ and elongation at break $\left(\varepsilon_{\mathrm{b}}\right) 69-448 \%$ [11, 14, 15]. In vivo studies have demonstrated that PGS degrades fully between 35 and 60 days by surface erosion. During degradation, PGS loses only $\sim 8 \%$ of its mechanical strength every week $[13,16]$, and its Young's modulus decreases by only $50 \%$ even after $\sim 70 \%$ degradation, which is an important characteristic many other polymeric biomaterials fail to achieve [16]. The disadvantage of PGS is that it requires high curing temperatures $\left(\sim 140{ }^{\circ} \mathrm{C}\right)$, long curing time (days) and high vacuum pressure, which limits the ability to fabricate a 3D porous scaffold [15]. Researchers have addressed this issue by chemically modifying the PGS synthesis (e.g. adding reactive acrylate moieties to produce poly(glycerol sebacate) acrylate, making it UV curable [17]) or using a second material to support the structure while curing (e.g. poly(glycerol sebacate)/poly(L-lactic acid) $[11,15])$. 
Recently Pereira et al. [18] introduced hexamethylene diisocyanate (HDI) that reacted with the hydroxyl groups of PGS to form a chemically crosslinked poly(glycerol sebacate urethane) (PGSU). This method has the advantage of using mild temperature $\left(55^{\circ} \mathrm{C}\right)$ for a short period (5 h) to crosslink the material followed by solvent removal. PGSU films were characterised and have been shown to be biocompatible, with a wide range of mechanical properties and tuneable degradation rate depending on the synthesis method and the amount of crosslinker [18]. In the previous work from our group, Frydrych and Chen [19] prepared large 3D PGSU scaffolds using freeze-drying, synthesised with three different HDI contents. Using this technique, a PGSU prepolymer solution was frozen at $-30^{\circ} \mathrm{C}$ and the solvent (1,4-dioxane) was sublimed directly from solid phase into vapour phase at $-5^{\circ} \mathrm{C}$ by reducing the chamber pressure, leaving a porous PGSU prepolymer scaffold followed by curing (at $37{ }^{\circ} \mathrm{C}$ for 48 hours) to obtain large 3D PGSU scaffolds [19, 20]. The effects that the crosslinker content has on the porous structure and physical properties of scaffolds were investigated. By increasing the crosslinker content, the porosity, pore size, tensile strength and elongation at break of the scaffold increased while the degradation rate reduced [19]. The scaffolds showed similar mechanical properties to those of human cardiac muscle and adipose tissue [19]. Another study from Frydrych et al. [21] fabricated PEGylated PGSU (PEU) bioelastomers and characterised their physical and biological properties in both dry and hydrated states. The mechanical properties, biodegradation rate and water swelling amount of the polymer can be modulated by varying the molecular weight of PEG [21]. Subsequently, Wang et al. [22] also synthesised PEU bioelastomer films and by varying the PEG and HDI contents the elastomers exhibited a large range of mechanical properties, degradation rate and water contact angle. The PEU elastomers demonstrated favourable biocompatibility in vitro and mild host response in vivo $[21,22]$. Another method of varying a scaffold's properties is to alter porous structure directly without changing the chemical structure of the polymer. A suitable porous structure is essential 
in a scaffold, as it is necessary for cell seeding and vascular ingrowth [23]. For example, polyurethane scaffolds were fabricated with two different porosities, $73 \%$ and $86 \%$, and were subcutaneously implanted on the back of 24 Winstar albino rats and examined for tissue ingrowth after 24 weeks. Significantly higher tissue ingrowth was found for the $86 \%$ porosity scaffolds [24]. A higher degree of porosity decreases stiffness and strength, but allows for bodily fluids to perfuse the structure more easily, and allows for more rapid ingrowth of host tissue [25].

Freeze drying is a scaffold fabrication technique, where a material is dissolved into a solvent which is frozen and removed by sublimation as mentioned above. It has the advantage of not using a high temperature compared to melt-based fabrication techniques (e.g., compression moulding, extrusion and injection moulding) which could have drawbacks such as denaturation of the polymer [26]. Furthermore, it does not require a separate leaching step as opposed to particular leaching which could result in particle residue that could affect the biocompatibility of the scaffold. Additionally, the freeze-drying technique enables control of pore size and porosity based on the freeze-drying procedure and freezing solution (e.g. polymer concentration) [20].

In this study freeze-drying was used to fabricate PGSU scaffolds with different pore sizes and porosities by varying the polymer concentration, aiming to determine their effect on the mechanical properties and degradation of the scaffold as well as the biological response to the scaffolds in vitro and in vivo. The microstructure of the scaffolds was determined by scanning electron microscopy (SEM), the mechanical properties were investigated by quasi-static, cyclic tensile testing and suture retention strength measurement, and the degradation rate was monitored in vitro using an enzyme that is relevant to the in vivo environment. The in vitro cell activity was studied using resazurin assay and Sirius red over 15 days of culture (measuring cell viability and matrix production), and the in vivo biological response was assessed using a 
chick embryo model to study tissue response and angiogenesis. The chick chorioallantoic membrane (CAM) assay is a functional angiogenesis assay which is used to measure the effect biomaterials have on angiogenesis, tissue ingrowth and tissue response ex ovo [27]. The new knowledge gained from this study will inform the development of PGSU scaffolds for a range of soft TE applications.

\section{Materials and Methods}

\subsection{Materials}

Sebacic acid (99\%), glycerol (>99\%), 1,4-dioxane (anhydrous, 99.8\%), hexamethylene diisocyanate (99\%), Tin(II) 2-ethylexanoate, lipase enzyme from porcine pancreas (54 U mg ${ }^{1}$ ), Dulbecco's modified eagle's medium (DMEM), penicillin-streptomycin (P/S), L-glutamine (200 mM), fetal calf serum (FCS), MEM non-essential amino acid solution (NEAA), HEPES buffer solution (1M), trypsin-ethylenediaminetetraacetic solution (trypsin/EDTA), resazurin sodium salt and direct red 80 were purchased from Sigma-Aldrich. Fertilised pathogen-free chicken eggs were purchased from Henry Stewart \& Co. Phosphate buffer saline (PBS) and Lascorbic acid were purchased from ThermoFisher Scientific and Mineral Water Chemical Supplies respectively.

\subsection{Methods}

\subsubsection{PGSU synthesis and scaffold fabrication}

The synthesis method of PGS pre-polymer was performed according to published methods [13, 28]. Briefly, 1:1 molar ratio of sebacic acid and glycerol were reacted at $120{ }^{\circ} \mathrm{C}$ for 72 hours under a low nitrogen gas flow while stirring. The protocol for synthesising PGSU was adopted from the work of Pereira et al [18] with some modifications [19]. Pre-PGS was firstly dissolved into 1,4-dioxane at the required concentrations $(5,10$ and $15 \mathrm{w} / \mathrm{v} \%)$ mixed with $0.05 \mathrm{w} / \mathrm{v} \%$ Tin(II) 2-ethylexanoate and pre-heated at $55{ }^{\circ} \mathrm{C}$. HDI was then added at a 0.6 molar ratio 
(glycerol:HDI) and left to react for 5 hours at $55^{\circ} \mathrm{C}$ under constant stirring. For PGSU films the solution was cast in a PTFE tray and left overnight to dry and further crosslinking. For porous scaffolds the solution was cast into an aluminium mould and placed into a freeze dryer (FreeZone Triad Dry System, Labconco Co., USA) that was precooled to $-50{ }^{\circ} \mathrm{C}$ and left for 3 $\mathrm{h}$ for the solution to completely freeze. The drying process then started with the shelf temperature heated at a rate of $1{ }^{\circ} \mathrm{C} / \mathrm{min}$ to $0{ }^{\circ} \mathrm{C}$ and left for $16 \mathrm{~h}$ under vacuum pressure $(0.1$ mbar). For the secondary drying stage the temperature was increased at a rate of $1{ }^{\circ} \mathrm{C} / \mathrm{min}$ to $40{ }^{\circ} \mathrm{C}$ for another $48 \mathrm{~h}$ [19] which also allowed further crosslinking of the polymer. The scaffolds were then washed with $100 \%$ ethanol for 24 h to remove any unreacted molecules (sol content shown in Table S1, Supplementary content) and the image of the scaffold is shown in Figure S1, Supplementary content. For ease of documentation, the nomenclature of the samples is PGSU-X where $\mathrm{X}$ refers to the polymer concentration (w/v\%), 5\%, $10 \%, 15 \%$ or film.

\subsubsection{Characterisation}

To examine the microstructure of the porous scaffolds an FEITM Inspect F50 SEM was utilised. The porous samples were attached on an aluminium stub and were gold coated using a High Resolution Polaron Sputter Coater at $15 \mathrm{kV}$ voltage for $1.5 \mathrm{~min}$. To measure the average pore diameter $(\mathrm{n}=50)$ ImageJ software was used.

The porosity of the scaffolds was measured using the gravimetric method [29]. Briefly, the densities of porous scaffold $\left(\rho_{s}\right)$ and film $\left(\rho_{f}\right)$ were calculated by dividing the mass with the volume of the sample, measured using a four-decimal point balance and a three-decimal calliper respectively. Five specimens were used from each batch of scaffolds. Knowing the density of the sample, equation (1) was then used to calculate the porosity,

$$
P=\left(1-\frac{\rho_{s}}{\rho_{f}}\right) \times 100
$$


PGSU porous scaffolds were tensile tested following the BS EN ISO 1798:2008 standard using a Hounsfield H100KS testing machine (Tinius Olsen, USA). The samples were prepared in dog-bone shape (using test sample cutter with gauge length $=25 \mathrm{~mm}$, width $=3.25 \mathrm{~mm}$ ) and tested at a $500 \mathrm{~mm} / \mathrm{min}$ rate of travel using a $10 \mathrm{~N}$ load cell until failure. Sufficient test pieces were used to provide 5 breaks within the gauge length. Same sample dimensions $(n=3)$ were also used for cyclic loading in which the samples were tensile loaded to $30 \%$ strain for 100 cycles at $100 \mathrm{~mm} / \mathrm{min}$ rate of travel using a $10 \mathrm{~N}$ load cell. The first and last cycles were recorded and plotted as strain-stress curves.

The suture retention strength was measured according to BS EN ISO 7198:2017 standard. The sample was cut normal to the long axis and a suture was inserted $2 \mathrm{~mm}$ from the end of the sample and a half loop was formed. The suture was then pulled, using a $10 \mathrm{~N}$ load cell, at $200 \mathrm{~mm} / \mathrm{min}$ and the force required to pull the suture through was recorded and plotted in grams. Five specimens were tested for each condition.

In vitro degradation was performed on the PGSU scaffolds using lipase enzyme from porcine pancreas at an activity of $40 \mathrm{U} / \mathrm{ml}[19,30]$. Prior to the experiment all samples were sterilised with $70 \%$ ethanol overnight, and then dried in a vacuum oven overnight at $40{ }^{\circ} \mathrm{C}$. The samples $(20 \times 5 \times 10 \mathrm{~mm})$ were fully submerged in triplicates into PBS/lipase solutions at an average mass to volume ratio of $3.2 \mathrm{mg} / \mathrm{ml}$ for a total of 28 days and placed in a shaker incubator at $37^{\circ} \mathrm{C}$ and $100 \mathrm{rpm}$, changing the enzyme solution every day. Every 7 days the samples were washed thoroughly with distilled water and dried in a vacuum oven at $25{ }^{\circ} \mathrm{C}$ overnight. The samples were then weighed, recorded, and then placed back into the enzyme solution. Samples were also degraded in PBS without enzymes as a control. 


\subsubsection{In vitro cell culture experiments}

L929 cells (immortalised mouse fibroblast cell line from ATCC, Middlesex, UK) were cultured using DMEM supplemented with fetal calf serum (FCS 10\% (v/v)), 2 mM L-Glutamine, 1\% NEAA, $100 \mathrm{IU} / \mathrm{ml}$ penicillin, $100 \mu \mathrm{g} / \mathrm{ml}$ streptomycin and $10 \mathrm{mM}$ HEPES).

PGSU scaffolds were prepared with diameter $=10 \mathrm{~mm}$, thickness $=2 \mathrm{~mm}$ in triplicates for each concentration. The samples were sterilised overnight with $70 \%$ ethanol and then under sterile environment washed thoroughly with PBS. The samples were then placed in a 12 wellplate and fixed within a $10 \mathrm{~mm}$ inner diameter stainless steel ring. The samples were passively seeded, by overlaying them with $200 \mu \mathrm{l}$ of cell/media suspension $\left(1.0 \times 10^{6}\right.$ cells/sample which amounts to $\sim 6000$ cells $/ \mathrm{mm}^{3}$ ) and topped up to $2 \mathrm{ml}$ after $2 \mathrm{~h}$ incubation. The next day the seeded scaffolds were moved to a fresh well-plate to ensure that any cell activity measured during the experiments was due to the cells on the scaffold. All the cell cultures were carried out for 15 days. Cells seeded on the tissue culture plastic (TCP) acted as positive control, and acellular scaffolds as negative control.

The cell metabolic activity was measured every 3 days using resazurin metabolic activity assay. Resazurin working solution was prepared by dissolving $0.25 \%(\mathrm{w} / \mathrm{v})$ resazurin sodium salt into media. The samples were washed 3 times with PBS, and $2 \mathrm{ml}$ of working solution was added to each sample and left in the incubator for $3 \mathrm{~h}$, wrapped in aluminium foil. Then, $200 \mu \mathrm{l}$ were transferred into a 96 well-plate in sextuplicate, and the fluorescence was read at $540 \mathrm{~nm}$ excitation, $590 \mathrm{~nm}$ emission on an absorbance plate reader (Bio-Tek ELx800). The samples were then washed three times and fresh media was added.

After 15 days culture the samples were fixed into $3.7 \%$ formaldehyde. The samples were paraffin-embedded and sectioned $(6 \mu \mathrm{m})$. The sections were dewaxed, rehydrated and stained with haematoxylin and eosin (H\&E). Live/dead assay fluorescent staining was not used in this 
case due to the high affinity of the fluorescent stain to the PGSU resulting in a significant background staining and hence invisible stained cells.

The collagen production was quantified using Sirius red stain (0.1\% (w/v) Direct Red 80 in saturated picric acid). The stain was added ( $2 \mathrm{ml}$ per sample) and left for $16 \mathrm{~h}$ to bind on the collagen. The excess stain was then removed by washing the sample with distilled water for 15 times. The samples were then dried in a vacuum oven at $25^{\circ} \mathrm{C}$, weighed and the stain was eluted using $2 \mathrm{ml}$ of $0.2 \mathrm{M} \mathrm{NaOH}$ :methanol 1:1 for $15 \mathrm{~min}$ on a rocking shaker. The absorbance was then measured at $490 \mathrm{~nm}$ in an absorbance plate reader (Bio-Tek ELx 800).

\subsubsection{Studies of angiogenic properties}

The CAM assay was carried out using the ex ovo method as described in [31] and complied with Home Office regulations. For this assay PGSU-5\% and PGSU-10\% scaffolds were used, with PGSU films acting as a control. Fertilised chicken eggs were incubated for 3 days in an R-Com King Suro 20 digital egg incubator at $37.8^{\circ} \mathrm{C}$. On day 3 post fertilisation, embryos were removed from their shells, transferred into sterile $100 \mathrm{ml}$ weighing boats with $2 \mathrm{ml}$ PBS containing $100 \mathrm{IU} / \mathrm{ml}$ penicillin, $100 \mu \mathrm{g} / \mathrm{ml}$ streptomycin, placed in petri dishes containing 12 $\mathrm{ml}$ distilled water to conserve humidity and incubated at $37{ }^{\circ} \mathrm{C}$ in a humidified cell culture incubator. On day 7 post fertilisation PGSU samples were placed onto the surface of each CAM and images taken of the samples with surrounding vasculature. Blood vessel growth towards the scaffold was imaged on days 12 post fertilisation using a Motorola USB microscope coupled with Microcapture imaging software. On day 13 the embryos were sacrificed and samples (including the attached CAM) were fixed in 3.7\% formaldehyde and were processed for histological analysis. Quantification of vascular growth was performed on blinded samples as per [32]. Briefly, images were greyscaled, sharpened, despeckled, sharpened again, adjusted using ImageJ before the blood vessels growing perpendicularly (within $\pm 45^{\circ}$ ) towards the samples were manually counted. 


\subsection{Statistics}

The statistical analysis was performed using one-way and two-way ANOVA with post hoc Tukey with null hypothesis set that there is no interaction between sample groups, using Graphpad Prism. All measurements were reported as mean \pm standard deviation (SD), and considered significant when $\mathrm{p} \leq 0.05$.

\section{Results}

\subsection{Characterisation of PGSU scaffold}

\subsubsection{Microstructure of the PGSU scaffolds}

Porous PGSU scaffolds were observed using SEM, and they presented a relatively uniform open pore interconnected structure in the centre of the cross-sectional areas (Figure 1A-C). Figure 1D shows the measured pore size and porosity from these areas. The pore size significantly decreased from $28.2 \pm 5.3 \mu \mathrm{m}$ to $16.1 \pm 2.6 \mu \mathrm{m}$, as the polymer concentration increased from $5 \%$ to $15 \%(\mathrm{w} / \mathrm{v})$. The same observation was found for porosity, with PGSU$5 \%$ the most porous $(96.4 \pm 0.3 \%)$, PGSU-15\% the least porous $(88.9 \pm 0.4 \%)$, and PGSU$10 \%$ in between $(92.3 \pm 0.7 \%)$. However, the pore structure remained similar, with stacked elongated pores and high uniformity. It was also found that the scaffolds exhibited different porous structures between their top, cross-section and bottom areas (Figure S3, Supplementary content), in part due to the low freezing temperature $\left(-50^{\circ} \mathrm{C}\right)$ and fast freezing used in this work (the solution was placed in the pre-cooled freeze dryer shelf for freezing). The pore sizes and porosities of the scaffolds at different areas are presented in Figure S4, Supplementary content. 

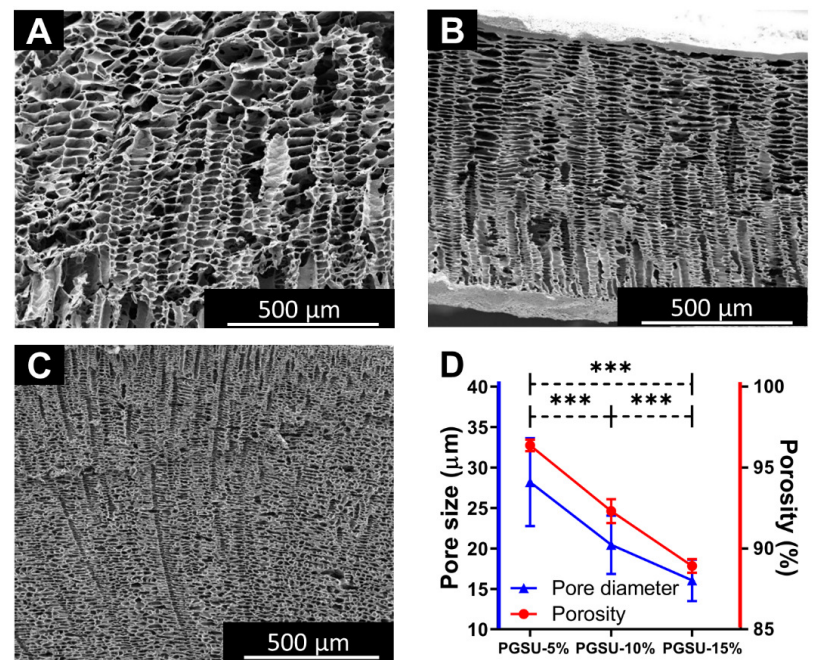

Figure 1: SEM images of porous (A) PGSU-5\%, (B) PGSU-10\% and (C) PGSU-15\% scaffolds with their measured (D) pore sizes and porosities. The SEM images were taken from the centre of the cross-section area of the scaffolds. (Results are shown mean \pm standard deviation, $\mathrm{n}=50$, *** when $\mathrm{p}<0.001$ )

\subsubsection{Mechanical Properties}

The scaffolds were subjected to tensile testing to examine their mechanical behaviour. Figure 2A shows the stress-strain curves of PGSU scaffolds fabricated with different polymer concentrations, and Figure 2B-D show the summary of the results. When the polymer concentration increased, so did the E, UTS and $\varepsilon$ with the highest values obtained from PGSU$15 \%$ equal to $0.65 \pm 0.18 \mathrm{MPa}, 0.86 \pm 0.21 \mathrm{MPa}$ and $122 \pm 19 \%$, respectively. The polymer concentration significantly affected E, which increased $\sim 9$ folds between PGSU-5\% and PGSU-10\%, 12 folds for PGSU-5\% against PGSU-15\% and 1.5 folds when comparing PGSU-10\% with PGSU-15\% (Figure 2B). Similar increases were found for the UTS, when comparing PGSU-5\% to PGSU-10\% it increased by $~ 9$ folds, PGSU-5\% to PGSU-15\% it increased $\sim 16$ folds and PGSU-10\% to PGSU-15\% it increased $\sim 2$ folds (Figure 2C). The elongation at break was only higher with statistical significance when comparing the values of PGSU-5\% and PGSU-15\% ( 1.3 folds higher) (Figure 2D). A negligible loss of tensile strength was observed for all three scaffolds after 100 tensile cycles, signifying the ability of the scaffold to recover its strength and shape after deformation (Figure 2E). Another mechanical property that was examined was the suture retention strength of the scaffolds, shown in Figure 2F. As 
expected the suture retention was significantly increased while the polymer concentration increased, with the highest force to be $247.5 \pm 37.5 \mathrm{~g}$, which is well above the surgical requirement (183 $\mathrm{g}$ [33], shown as dotted line).
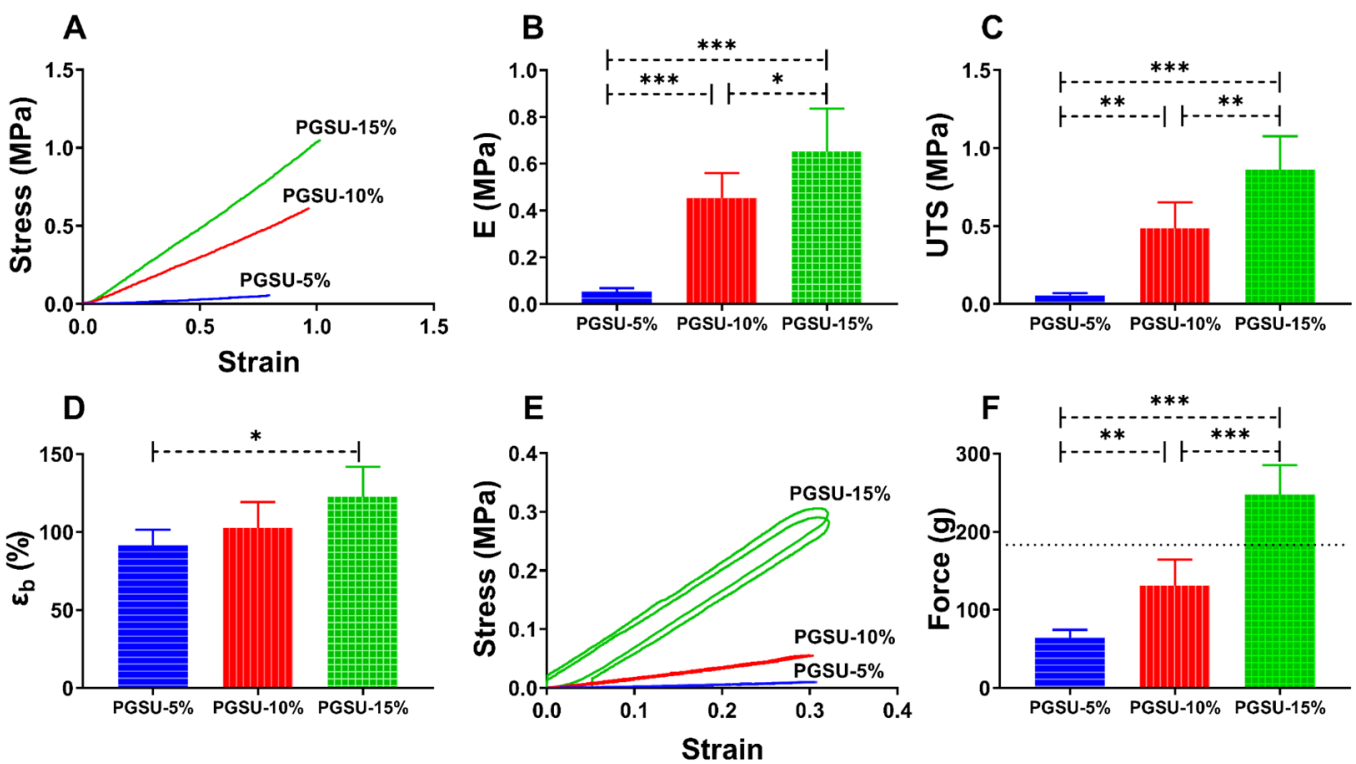

Figure 2: (A) Representative tensile stress-strain curves, (B) Young's modulus, (C) ultimate tensile strength, (D) elongation at break, (E) cyclic loading curves, and (F) suture retention strength of the PGSU scaffolds. (Results are shown mean \pm standard deviation, $\mathrm{n}=5$, * when $\mathrm{p}<0.05$, ** when $\mathrm{p}<0.01$ and $* * *$ when $\mathrm{p}<0.001$ )

\subsubsection{In-vitro biodegradation}

Figure 3 shows the mass loss of the scaffolds over time degraded in lipase-containing PBS solution, with enzyme-free PBS as a control. When the concentration of polymer was increased, the degradation rate decreased. In lipase PGSU-5\% degraded $52.3 \pm 3.8 \%$, a slightly slower degradation rate was observed for PGSU-10\% with mass loss equal to $39.3 \pm 3.9 \%$ and consequently, the highest concentration, PGSU-15\%, exhibited an even smaller mass loss of $19.1 \pm 1.0 \%$. For the scaffolds degrading in the PBS without the enzyme there was only minimal mass losses observed $(\mathrm{PGSU}-5 \%=1.99 \pm 0.55 \%, \mathrm{PGSU}-10 \%=0.47 \pm 0.23 \%, \mathrm{PGSU}-$ $15 \%=0.22 \pm 0.19 \%$ ) from all three scaffolds with no significant difference between the groups. 


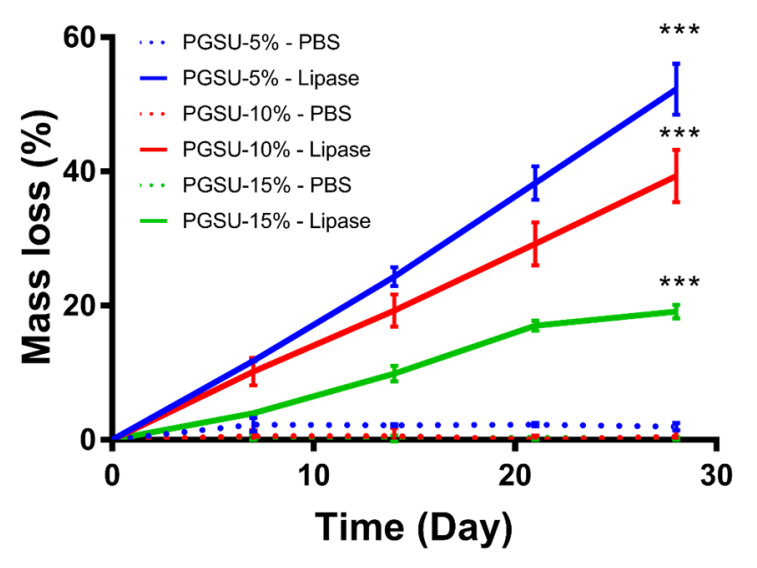

Figure 3: In-vitro enzymatic degradation of PGSU5\%, 10\% and 15\% scaffolds. Samples were degraded in PBS as a control. (Results are shown mean \pm standard deviation, $\mathrm{n}=3$, *** when $\mathrm{p}<0.001$ )

\subsection{Cell culture}

\subsubsection{Cell activity}

Scaffolds in TE must provide the cells with a viable environment in order for them to adhere and proliferate. To test this, the scaffolds were seeded with L929 mouse fibroblast cells, which are the cells specified by BS EN ISO 10993-5:2009 for biological evaluation of medical devices and the results are shown in Figure 4. Over 15 days culture the cell activity significantly increased every 3 days reaching $\sim 4$ times higher cell activity. No significant difference was found between polymer concentration groups and no increase was observed following day 12 suggesting cell confluence was reached.

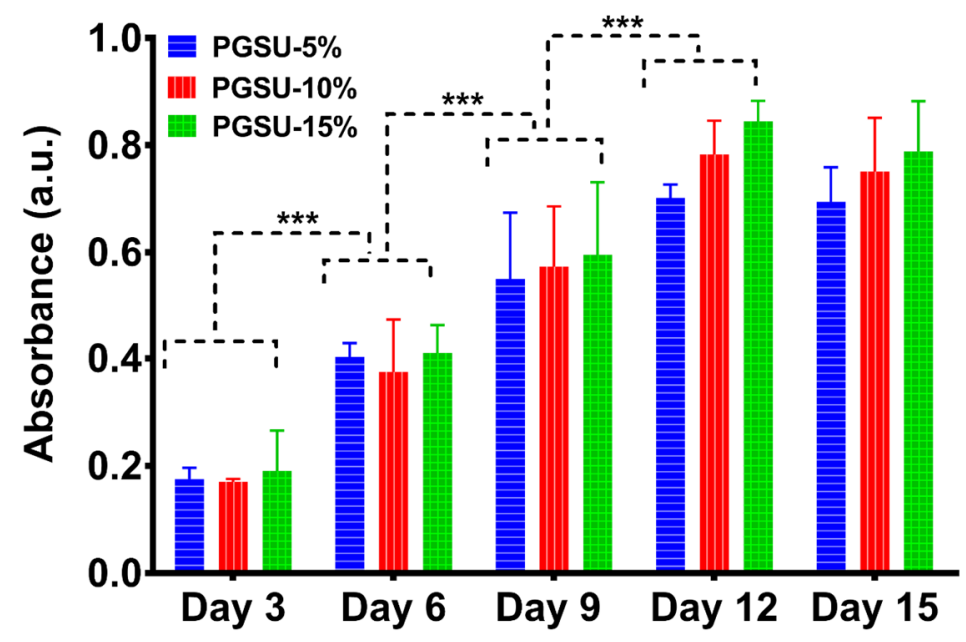


Figure 4: Cell activity of L929 cells seeded on PGSU-5\%, 10\% and 15\% scaffolds measured by resazurin assay. Arbitrary unit $=$ a.u. (Results are shown mean \pm standard deviation, $\mathrm{n}=3$, *** when $\mathrm{p}<0.001$ )

The samples were fixed and sectioned at the end of the 15 days culture and histological analysis was performed to observe their cross section, shown in Figure 5. Cells were attached onto all the three types of the scaffold, with a dense cell layer on the seeding surface (i.e., top surface). When comparing the cell penetration inside the scaffolds, the cells penetrated deeper for the PGSU-5\%, and less penetration was found in the scaffold with the higher polymer concentrations.
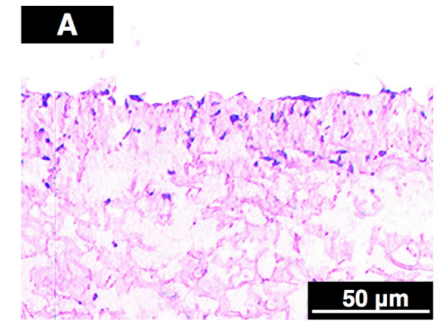

B

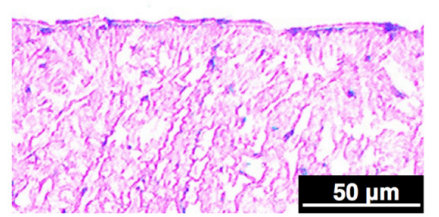

\section{C}

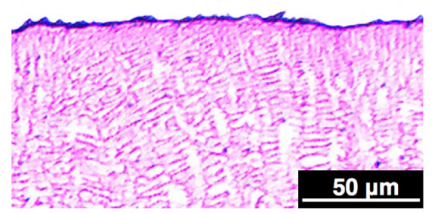

Figure 5: Histological analysis (H\&E staining) of the cell seeded PGSU scaffolds for all three concentrations (A) PGSU-5\%, (B) PGSU-10\% and (C) PGSU-15\%.

\subsubsection{Collagen content}

Figure 6 shows the results of the collagen content (collagen / dry sample (w/w\%)) measured by Sirius red on cell seeded scaffolds cultured for 15 days. The PGSU-5\% showed a significantly higher collagen content, $7.5 \pm 2.6 \%$, compared to the PGSU-10\%, $1.7 \pm 0.6 \%$, and PGSU-15\%, $0.4 \pm 0.3 \%$. Macroscopic images of the stained PGSU samples were also taken and are shown in Figure S5, Supplementary content, which demonstrated difference in colour intensity prior to eluting the stain. SEM images were also taken looking at the cross section of the samples after the 15 days cell culture (Figure 6B, D). The SEM images demonstrated that the original, highly porous PGSU-5\% scaffold had an enclosed pore structure due to the newly-produced collagen and other extra-cellular matrix (ECM) deposition, which was less visible in other polymer concentration scaffolds. 


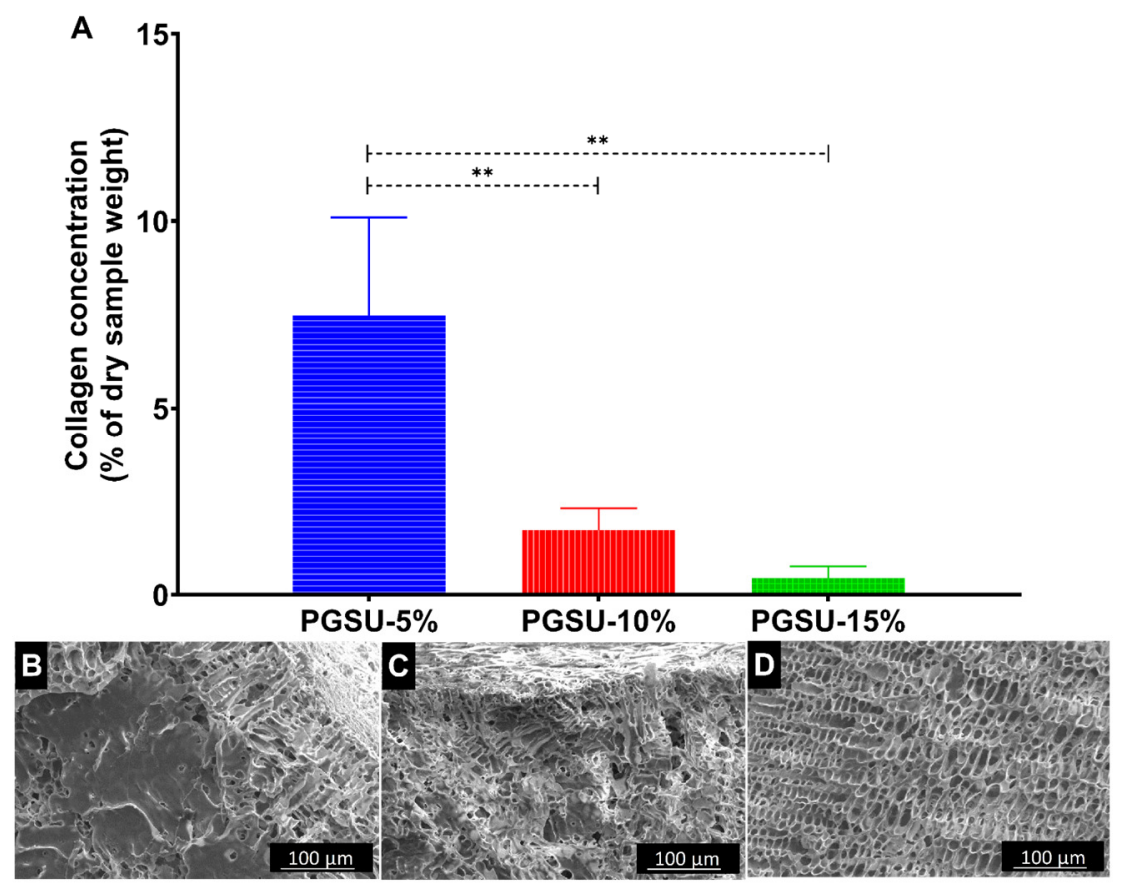

Figure 6: (A) Collagen content as a percentage of the dry sample's mass deposited by L929 cells after 15 days of culture. SEM images of (B) PGSU-5\%, (C) PGSU-10\% and (D) PGSU-15\% from the cross section of the scaffolds after culture. (Results are shown mean \pm standard deviation, $\mathrm{n}=3$, $* *$ when $\mathrm{p}<0.01$ )

\subsection{Angiogenic properties}

The ability of new blood vessels to penetrate PGSU scaffolds with different surface pore sizes was tested with the ex ovo CAM assay. In this assay the chick membrane was in contact with the bottom surface of PGSU-5\% and PGSU-10\% scaffolds and it is expected the size of the pores on the bottom surface of the scaffold contributed more to our observations compared to the cross-sectional pore size. PGSU-5\% and PGSU-10\% scaffolds with surface pore sizes of $26.5 \pm 5.5 \mu \mathrm{m}$ and $11.0 \pm 2.2 \mu \mathrm{m}$ respectively (Figure S4, Supplementary content) were compared to non-porous PGSU-film samples to assess the effect of pore size on angiogenesis and tissue ingrowth. The addition of PGSU scaffolds to the CAM did not affect the viability of the chick embryos used compared to control PGSU-film sample. Figure 7 shows the development of and changes in the chorioallantoic membrane vasculature between days 7 and 12 following implantation with PGSU-film (A1, A2), PGSU-5\% scaffold (B1, B2) and PGSU$10 \%$ scaffold $(\mathrm{C} 1, \mathrm{C} 2)$. Following 5 days incubation with the PGSU-scaffolds more vessels were observed growing towards the scaffolds. In contrast, the chick vasculature appears to be 
unaffected by the presence of the PGSU in the PGSU-film samples, with vasculature developing as is observed in untreated samples. Figure 7D shows the increase in the number of new blood vessels growing perpendicularly towards each scaffold between days 7 and 12 . The CAM exposed to PGSU films did not demonstrate any change in the number of vessels growing towards the sample, however the PGSU-5\% samples showed an average increase of 10.3 vessels while the PGSU-10\% samples showed an average increase of 2.3 vessels which is significantly lower than the lower concentration scaffolds (PGSU-5\%) but significantly higher than the control (PGSU-film) sample.
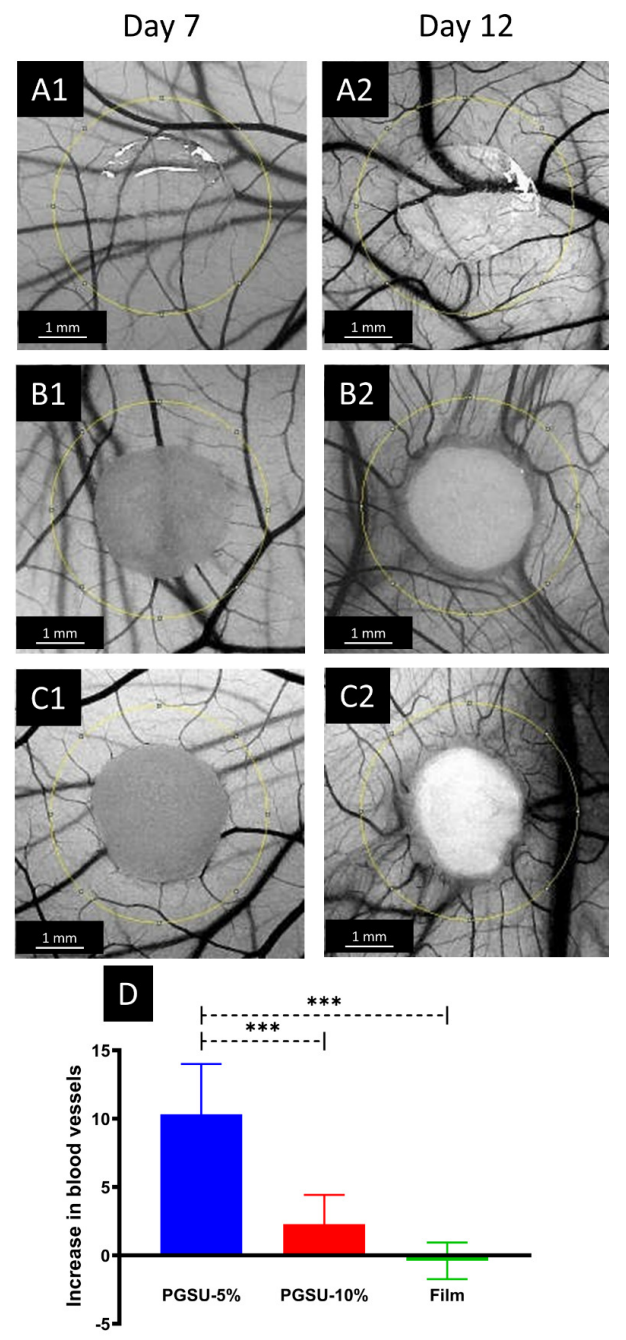

Figure 7: Optical micrographs of (A1, 2) PGSU-film, (B1, 2) PGSU-5\% scaffold and (C1, 2) PGSU-10\% scaffold and surrounding vasculature on CAM at 7 and 12 days post fertilisation. Yellow line shows position of vessel ingrowth measurements. The graph (D) shows the increase in number of blood vessels growing towards the samples between day 7 and 12. (Results are shown mean \pm standard deviation, $\mathrm{n}=3$, *** when $\mathrm{p}<0.001$ ) 
During histological processing the PGSU-film detached from the CAM however the membrane adjacent to the film samples remained well-defined (as labelled in Figure 8A, B) and the allantoic membrane was uniform and undisturbed.

The PGSU-5\%, shown in Figure 8C, D, had undergone complete tissue integration, with the allantoic epithelium being completely indistinguishable. Ingrown tissue was dense and mostly devoid of gaps, with some evidence of primitive blood vessel formation (indicated by arrows showing the round vessel like structures containing nucleated chick red blood cells). Tissue ingrowth was observed as deep as $0.8 \mathrm{~mm}$ with most pores being densely filled by cells.

The PGSU-10\% scaffold (Figure 8E, F) showed very limited tissue integration, with only the sides of the sample exhibiting some ingrowth (where pore size is larger). Even on the sides of the sample, the tissue was unable to penetrate the sample to any considerable depth $(0.1$ $\mathrm{mm})$.
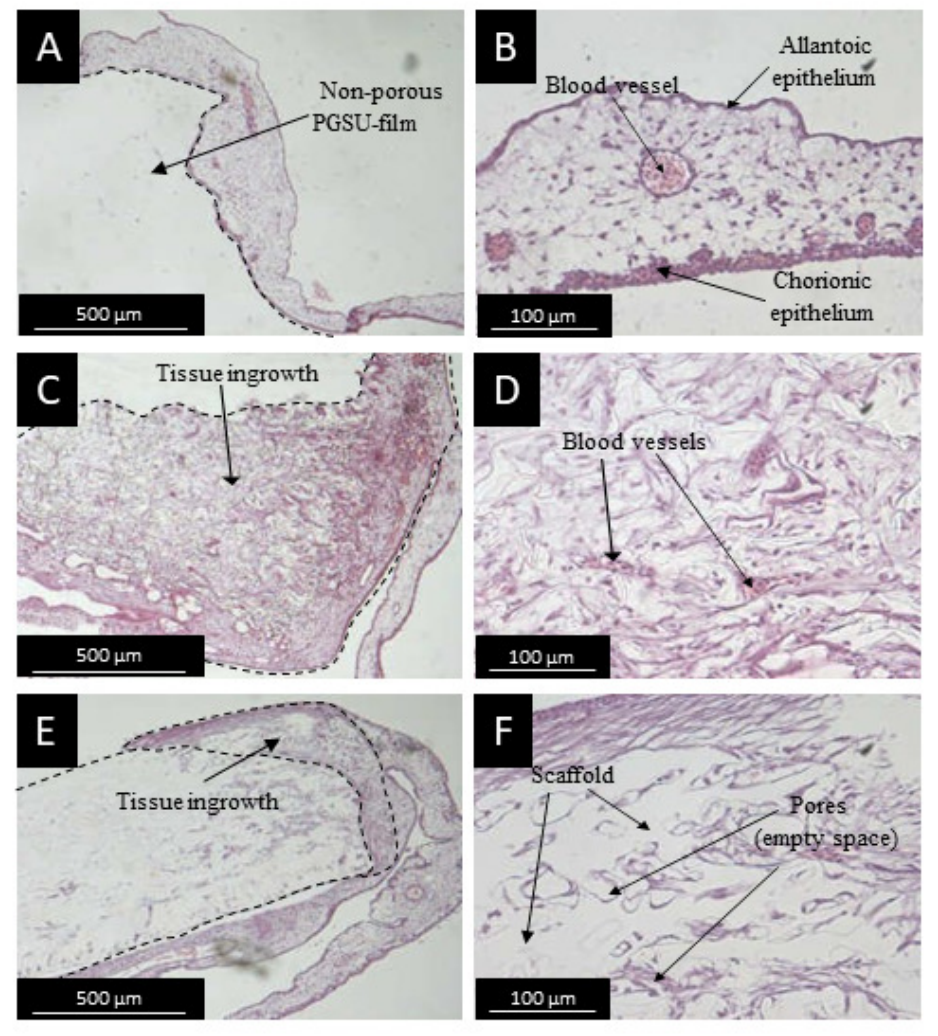

Figure 8: H\&E stained histological images of (A, B) PGSU-film, (C, D) PGSU-5\% and (E, F) PGSU-10\% and surrounding CAM fixed on day 13 . The film itself $(\mathrm{A}, \mathrm{B})$ is not visible as it did not remain attached to the CAM following histological processing. 


\section{Discussion}

For the first time large 3D PGSU scaffolds were assessed for their in vitro cell biocompatibility, ex ovo tissue response and angiogenesis. To perform this study, we synthesised and fabricated porous PGSU scaffolds with various microstructures and physical properties as both have been shown to affect the cell biocompatibility, tissue ingrowth and angiogenesis [24, 34].

The main findings were that the PGSU scaffolds with larger pore size and higher porosity (PGSU-5\%) stimulated a large amount of collagen production and a rapid angiogenesis as well as deep tissue ingrowth during CAM assay.

The synthesis procedure of PGSU was reported before in $[15,18,19,35]$ and this study followed similar procedures. This study began by examining the chemical structure of PGSU using attenuated total reflection - Fourier transform spectroscopy (ATR-FT-IR) that confirmed the successful synthesis and chemical structure of PGSU, shown in Figure S2, Supplementary content. The results closely resembled the results of Pereira et al. [18] and Frydrych and Chen [19] even with the synthesis modification. Additionally, the absence of the characteristic HDI peak $\left(2250 \mathrm{~cm}^{-1}\right)$ from the PGSU spectrum, demonstrated a complete reaction of the isocyanate groups with the hydroxyl groups.

During freeze drying the pores in the scaffold are dependent on the freezing process, as the ice crystals formed during freezing leave a pore in the scaffold after it has sublimed. In this study, we freeze dried the scaffolds using the same freeze-drying cycle, but with different concentrations of the polymer in the freeze-drying solution. The results demonstrate that altering the polymer concentration is an effective way to control pore size as well as the porosity of the scaffold during freeze-drying, in line with the literature $[23,36]$. The porosity decreased significantly when polymer concentration increased, and we obtained higher porosity compared to previously reported PGSU scaffolds $(87.9 \pm 1.3 \%)$ that used a lower polymer concentration of $2.6 \%$ [19]. This increased porosity is thought to be due to different 
freezing conditions and different moulds used in these two studies as these parameters are known to affect the final porous structure [37]. Our findings are that in all cases the scaffolds demonstrated a highly porous structure with interconnected pores.

Tissue engineering scaffolds need to have mechanical strength sufficient to withstand physiological in vivo forces and to maintain integrity until it is replaced by the newly formed tissue. The material itself plays an important role on the mechanical properties of the scaffold but the microstructure does as well. With this in mind there should be a good balance between pore size, porosity and mechanical properties, to facilitate cell infiltration, angiogenesis and mechanical stability [29]. Native soft tissues' elastic behaviour is strongly influenced by ECM structural arrangement. For example soft tissues such as skin and aorta have UTS between 1$20 \mathrm{MPa}$ and $0.3-0.8 \mathrm{MPa}$ respectively, and their $\varepsilon_{\mathrm{b}}$ is $30-70 \%$ and $50-100 \%$, while tendon and ligaments exhibit UTS ranging 50-100 MPa and $\varepsilon_{\mathrm{b}} 10-15 \%[38,39]$. The PGSU scaffolds fabricated in this work were highly flexible and there was no yielding found before failure despite the high porosity. The UTS of the scaffolds $(0.05-0.86 \mathrm{MPa})$ is comparable to aorta and the $\varepsilon_{\mathrm{b}}(91.42-122.6 \%)$ is also sufficient to replicate the same elongation and flexibility. Furthermore, during the cyclic loading experiment, all scaffolds showed a negligible loss of mechanical strength after 100 cycles to $30 \%$ strain, indicating that these scaffolds can recover their mechanical strength after deformation making them suitable for flexible soft tissue applications where both strength and elasticity is required. This property is an advantage over some other polymeric scaffolds such as PLGA, PCL and PEG which were reported to undergo plastic deformation after tensile testing, making them non-ideal to be used in soft TE [10].

The polymer concentration had a more significant effect on the mechanical properties of the PGSU scaffolds in this study compared to the HDI content of the PGSU scaffolds fabricated by Frydrych and Chen [19]. In the previous work, it was found that by increasing the HDI content of the PGSU scaffolds the E decreased from $40 \mathrm{kPa}$ to $30 \mathrm{kPa}$ and the UTS increased 
$18 \mathrm{kPa}$ to $22 \mathrm{kPa}$, while the $\varepsilon_{\mathrm{b}}$ increased from $49 \%$ to $82 \%$ [19], which are all lower than the values reported in this study owing to their different porosities and porous structures as well as chemical structures of the PGSU. In another work of Frydrych et al. [21], PEU films were fabricated with multiple PEG molecular weights and it was found that the higher the molecular weight of PEG the higher the E, UTS and $\varepsilon_{b}$. A subsequent study regarding PEU by Wang et al. [22] investigated the effect of changing both the content of PEG and HDI and found that the highest UTS and E occurred when using the highest amount of HDI. Consequently, altering the reactants, polymer molecular weight and/or molar ratio of the reactants affects the mechanical properties of PGSU [18, 19] and PEU [21, 22] films, and in terms of PGSU scaffold, these parameters were less effective in changing its mechanical properties [19] when compared to varying the polymer concentration in the freeze-drying solution.

Biomaterials usually are manipulated before transplantation therefore they should maintain their structure and mechanical integrity prior to transplantation [18]. When a scaffold is implanted in most cases it is sutured at the implantation site, thus the suture retention strength of the scaffold needs to be characterised. It was reported that the suture retention surgical requirement is $1.8 \mathrm{~N}$ (or $183 \mathrm{~g}$, shown with dotted line Figure 2F) [33], and the PGSU-15\% scaffold had a higher suture retention strength than the surgical requirement meaning that it can be securely sutured on the implantation site without structure failure.

The degradation mechanism of PGSU is based on surface erosion [18, 19]. Lipase can catalyse the hydrolysis of ester bonds, hence it is one of the most common enzymes used when examining the in vitro degradation characteristics of polyester materials $[11,15,40]$. Degrading the PGSU samples in vitro with lipase shows a linear degradation rate dependent on the polymer concentration. The polymer concentration affects the degradation kinetics by influencing the surface area exposed to the enzyme, and since PGSU degrades by surface erosion, the degradation rate is decreased with increasing polymer concentration. Previous 
work has shown that the surface to volume ratio has a significant effect on the degradation rate of the scaffold, which is in agreement with the results of this study [41]. The linear degradation observed from these scaffolds is also found from PGS scaffolds, and another property that they exhibit is PGS samples retain their mechanical properties while degrading, losing mechanical strength at a lower rate than mass loss $[13,16]$.

Pereira et al. examined PGSU films in vitro for their cell biocompatibility using MTT assay concluding no adverse effect on cell activity [18]. The in vitro cell biocompatibility results from this study showed the scaffolds supported cell adhesion and an increase in cell activity over time with no adverse effects. These results mean that the scaffolds provided a surface for the cells to adhere and proliferate. Many previous studies have shown that the cell metabolic activity is influenced significantly by pore size and porosity [29]. In this study, no changes in cell metabolic activity were observed when pore size and porosity were altered within the range studied. However, the cell penetration and cell distribution were affected (Figure 5). When the scaffolds were histologically analysed it was observed that the cells could penetrate less when the pore size was smaller. These findings are assumed to be due to the smaller pore size of the top surface of the scaffolds where cells were seeded, shown in Figure S4, Supplementary content. The PGSU-15\% has a significantly smaller pore size $(6.4 \mu \mathrm{m})$ on the top surface compared to within the scaffold. These small pores were not sufficient to allow the cells to penetrate but provided a surface for them to attach, adhere and proliferate. The reason this smaller pore size surface is formed is because during pre-freezing stage the 1,4-dioxane freezes faster at the top surface resulting in smaller pores compared to the internal structure. If required, this top surface can be removed by slicing it off in further studies to enhance the cell penetration and distribution.

Natural ECM is largely composed of collagen; therefore, it is important to examine if the cells adhered to the scaffold produced collagen. The tissues we aim to replace are 
predominantly collagen therefore as scaffold degrades new collagen should be produced to replace the scaffold's structural support. Additionally, previous research studies have presented that newly produced collagen can increase or maintain the mechanical properties of the scaffold, thus the scaffold maintains its structure integrity allowing enough time for the new tissue to completely replace it $[42,43]$. The PGSU-5\% was characterised with a significantly higher collagen amount $(7.5 \pm 2.6 \%$ of dry sample weight $)$ compared to the other two scaffolds, which can be explained with better cell penetration, distribution and higher surface area [44]. For comparison reasons, the collagen in cartilage accounts for $10-20 \%$ of the dry weight of cartilage, in tendon/ligaments $70-80 \%$, aorta $25-35 \%$ and skin $60-80 \%[39,45]$. In this study we demonstrated that PGSU-5\% encouraged collagen production reaching collagen amount close to cartilage tissue in 15 days static cell culture. Longer cell culture should be examined to determine if the collagen amount further increases over time.

There is evidence that pore size has a dramatic effect on cell mobility and differentiation, and this in turn may lead to a change to ingrowth of cells and blood vessels [23, 24]. Research into the optimum pore size for blood vessel ingrowth varies in the literature most probably because of different biomaterials used, however it was generally shown that the larger the pores the better the angiogenic properties. For example, one study of beta-tricalcium phosphate scaffolds with $150 \mu \mathrm{m}$ pore size implanted into the bone defect of rabbit femoral condyles promoted angiogenesis most effectively when compared to 100 and $120 \mu \mathrm{m}$ pore sizes [46]. Another study claimed PCL scaffolds with $300 \mu \mathrm{m}$ pore size implanted into the omentum of Lewis rats had the optimal pore size compared to the cases with 80 and $160 \mu \mathrm{m}$ pore sizes [47]; and another claims that PEG hydrogels with pores equal to $42 \mu \mathrm{m}$ implanted between rat fascia and muscle allow significantly smaller vessel invasion compared to $82 \mu \mathrm{m}$ and $135 \mu \mathrm{m}$ [48].

In this work, we showed that the PGSU-5\% scaffold had a higher angiogenic response when compared to the scaffold with a smaller pore size and lower porosity (PGSU-10\%) (Figure 7), 
in line with previous studies [35]. The PGSU-10\% can be seen to increase the number of blood vessels growing towards the scaffold when implanted on the CAM assay, however this is not significantly different to the film and is not as pronounced as for the PGSU-5\% scaffold. The pore size for the bottom surface that is in contact with the PGSU-10\% is significantly lower as opposed to that of the PGSU-5\% $(11.0 \pm 2.2 \mu \mathrm{m}$ versus $26.5 \pm 5.5 \mu \mathrm{m})$.

Histological analysis shows some degree of tissue ingrowth (Figure 8); however, for the PGSU-10\%, the tissue is only able to penetrate the sides of the sample where the pores are slightly larger. For the larger pore size scaffold, PGSU-5\% samples elicited dense, well integrated ingrowth that appears to show signs of blood vessel formation, as deep as $0.8 \mathrm{~mm}$ into the sample. The CAM is comprised of embryonic tissue which will have a higher regenerative and angiogenic capacity compared to an adult wound where these scaffolds may be used however the results are strongly encouraging. Of particular interest is that these results have been observed with no biochemical stimuli, such as vascular endothelial growth factor, fibroblast growth factor and endothelin. It is worth mentioning that a PGSU scaffold with a larger pore size (PGSU-2.5\%, bottom surface pore size $=128.7 \pm 15.3 \mu \mathrm{m}$, cross-section pore size $=96.2 \pm 19.8 \mu \mathrm{m}$ and porosity $=96.9 \pm 0.7 \%$ ) has also been fabricated and examined for its angiogenic properties to determine if increasing pore size and porosity continues to have a positive effect on angiogenesis as in the cases reported in literature discussed before (Figure S6, Supplementary content). Briefly, it was found that there was a considerable level of tissue integration with approximately $\sim 0.7 \mathrm{~mm}$ ingrowth; however, the tissue was less dense than the one grown into PGSU-5\% leading to ineffectively filled pores, leaving large gaps where the tissue has appeared to have been unable to bridge the gaps between pore walls. Additionally, blood cells were leaking into the tissue, probably due to the poor development of vascular structures, caused by lack of structural support. Therefore, from this study it was found that for the PGSU scaffolds to have an adequate vascularisation and tissue ingrowth capabilities, their 
microstructure features, namely pore size and porosity, should have an optimum range (exhibited from PGSU-5\%) and altering these features has an adverse effect by either not providing structural support to the tissue integration (as in the case of PGSU-2.5\%) or not porous enough (as in the case of PGSU-10\%).

\section{Conclusions}

The findings of this study demonstrate the ability of large 3D PGSU scaffolds with appropriate porous structure and porosity to facilitate cell proliferation, high collagen production and a positive angiogenic response. The PGSU scaffolds exhibited elastomeric properties that could be stretched to almost double their initial length, demonstrated a negligible loss in mechanical strength after cyclic loading, suture retention strength close to the surgical requirement and linear enzymatic degradation, helping fill a gap in existing biomaterials for soft tissue engineering. Regarding the microstructure effect on the biological response of the scaffolds, it was found that the smaller pore size of the highest concentration scaffolds negatively affected the cell penetration and consequently reduced the collagen production. While the scaffold degrades it is important to allow its replacement by newly formed tissue and blood vessels to support the viability of the tissue. In this study, it was found that the PGSU-5\% scaffolds with medium range pore size $(\sim 26-28 \mu \mathrm{m})$ and high porosity $(96 \%)$ promoted tissue and blood vessel ingrowth, without the need for additional biochemical stimuli. It is therefore considered that PGSU scaffolds have potential to be further tuned and used in the engineering of soft tissues where flexibility and mechanical strength are required and are in dynamic in vivo environments such as skin, oral mucosa, blood vessels and ligaments.

\section{References}

[1] S.Q. Liu, Bioregenerative Engineering: Principles and Applications, Wiley Interscience 2007. 
[2] G. Shi, Q. Cai, C. Wang, N. Lu, S. Wang, J. Bei, Fabrication and biocompatibility of cell scaffolds of poly(L-lactic acid) and poly(L-lactic-co-glycolic acid), Polymers for Advanced Technologies 13(3-4) (2002) 227-232.

[3] G. Vunjak-Novakovic, R.I. Freshney, Culture of cells for tissue engineering, Wiley-Liss, Hoboken, N.J., 2006.

[4] S. Sakiyama-Elbert, J. Hubbell, Functional Biomaterials: Design of Novel Biomaterials, Annual Review of Materials Research 31(1) (2001) 183-201.

[5] M.W. Laschke, Y. Harder, M. Amon, I. Martin, J. Farhadi, A. Ring, N. Torio-Padron, R. Schramm, M. Rucker, D. Junker, J.M. Haufel, C. Carvalho, M. Heberer, G. Germann, B. Vollmar, M.D. Menger, Angiogenesis in tissue engineering: breathing life into constructed tissue substitutes, Tissue Eng 12(8) (2006) 2093-104.

[6] T. Serra, J.A. Planell, M. Navarro, High-resolution PLA-based composite scaffolds via 3D printing technology, Acta Biomaterialia 9(3) (2013) 5521-5530.

[7] H.N. Chia, B.M. Wu, High-resolution direct 3D printed PLGA scaffolds: print and shrink, Biofabrication 7(1) (2014) 015002.

[8] H. Seyednejad, D. Gawlitta, R.V. Kuiper, A. de Bruin, C.F. van Nostrum, T. Vermonden, W.J.A. Dhert, W.E. Hennink, In vivo biocompatibility and biodegradation of 3D-printed porous scaffolds based on a hydroxyl-functionalized poly( $\varepsilon$-caprolactone), Biomaterials 33(17) (2012) 4309-4318.

[9] L.A. Hockaday, K.H. Kang, N.W. Colangelo, P.Y. Cheung, B. Duan, E. Malone, J. Wu, L.N. Girardi, L.J. Bonassar, H. Lipson, C.C. Chu, J.T. Butcher, Rapid 3D printing of anatomically accurate and mechanically heterogeneous aortic valve hydrogel scaffolds, Biofabrication 4(3) (2012) 035005.

[10] Y.C. Yeh, C.B. Highley, L. Ouyang, J.A. Burdick, 3D printing of photocurable poly(glycerol sebacate) elastomers, Biofabrication 8(4) (2016) 045004.

[11] M. Frydrych, S. Roman, S. MacNeil, B. Chen, Biomimetic poly(glycerol sebacate)/poly(L-lactic acid) blend scaffolds for adipose tissue engineering, Acta biomaterialia 18 (2014) 40-49.

[12] M. Radisic, J. Malda, E. Epping, W. Geng, R. Langer, G. Vunjak-Novakovic, Oxygen gradients correlate with cell density and cell viability in engineered cardiac tissue, Biotechnol Bioeng 93(2) (2006) 332-43.

[13] Y. Wang, G.A. Ameer, B.J. Sheppard, R. Langer, A tough biodegradable elastomer, Nat Biotech 20(6) (2002) 602-606.

[14] Q.-Z. Chen, A. Bismarck, U. Hansen, S. Junaid, M.Q. Tran, S.E. Harding, N.N. Ali, A.R. Boccaccini, Characterisation of a soft elastomer poly(glycerol sebacate) designed to match the mechanical properties of myocardial tissue, Biomaterials 29(1) (2008) 47-57.

[15] M. Frydrych, B. Chen, Large three-dimensional poly(glycerol sebacate)-based scaffolds - a freeze-drying preparation approach, Journal of Materials Chemistry B 1(48) (2013) 66506661.

[16] Y. Wang, Y.M. Kim, R. Langer, In vivo degradation characteristics of poly(glycerol sebacate), Journal of Biomedical Materials Research Part A 66A(1) (2003) 192-197.

[17] R. Rai, M. Tallawi, A. Grigore, A.R. Boccaccini, Synthesis, properties and biomedical applications of poly(glycerol sebacate) (PGS): A review, Progress in Polymer Science 37(8) (2012) 1051-1078.

[18] M.J. Pereira, B. Ouyang, C.A. Sundback, N. Lang, I. Friehs, S. Mureli, I. Pomerantseva, J. McFadden, M.C. Mochel, O. Mwizerwa, P. Del Nido, D. Sarkar, P.T. Masiakos, R. Langer, L.S. Ferreira, J.M. Karp, A highly tunable biocompatible and multifunctional biodegradable elastomer, Adv Mater 25(8) (2013) 1209-15.

[19] M. Frydrych, B. Chen, Fabrication, structure and properties of three-dimensional biodegradable poly(glycerol sebacate urethane) scaffolds, Polymer 122 (2017) 159-168. 
[20] K. Scoffin, Scaling the Scaffolds: Control of Pore Size in Tissue Engineering Scaffolds, American Laboratory (2011).

[21] M. Frydrych, S. Román, N.H. Green, S. MacNeil, B. Chen, Thermoresponsive, stretchable, biodegradable and biocompatible poly(glycerol sebacate)-based polyurethane hydrogels, Polymer Chemistry 6(46) (2015) 7974-7987.

[22] Z. Wang, Y. Ma, Y. Wang, Y. Liu, K. Chen, Z. Wu, S. Yu, Y. Yuan, C. Liu, Urethanebased low-temperature curing, highly-customized and multifunctional poly(glycerol sebacate)co-poly(ethylene glycol) copolymers, Acta Biomaterialia 71 (2018) 279-292.

[23] F.J. O'Brien, B.A. Harley, I.V. Yannas, L.J. Gibson, The effect of pore size on cell adhesion in collagen-GAG scaffolds, Biomaterials 26(4) (2005) 433-41.

[24] T.G. van Tienen, R.G.J.C. Heijkants, P. Buma, J.H. de Groot, A.J. Pennings, R.P.H. Veth, Tissue ingrowth and degradation of two biodegradable porous polymers with different porosities and pore sizes, Biomaterials 23(8) (2002) 1731-1738.

[25] S.J. Hollister, Porous scaffold design for tissue engineering, Nat Mater 4(7) (2005) 51824.

[26] R.M. Allaf, Melt-molding technologies for 3D scaffold engineering, in: Y. Deng, J. Kuiper (Eds.), Functional 3D Tissue Engineering Scaffolds, Woodhead Publishing2018, pp. 75-100.

[27] G. Gigliobianco, C.K. Chong, S. MacNeil, Simple surface coating of electrospun poly-Llactic acid scaffolds to induce angiogenesis, J Biomater Appl 30(1) (2015) 50-60.

[28] J. Gao, P.M. Crapo, Y. Wang, Macroporous elastomeric scaffolds with extensive micropores for soft tissue engineering, Tissue Eng 12(4) (2006) 917-25.

[29] Q.L. Loh, C. Choong, Three-Dimensional Scaffolds for Tissue Engineering Applications: Role of Porosity and Pore Size, Tissue Engineering. Part B, Reviews 19(6) (2013) 485-502.

[30] S.L. Liang, X.Y. Yang, X.Y. Fang, W.D. Cook, G.A. Thouas, Q.Z. Chen, In Vitro enzymatic degradation of poly (glycerol sebacate)-based materials, Biomaterials 32(33) (2011) 8486-8496.

[31] D.S. Dohle, S.D. Pasa, S. Gustmann, M. Laub, J.H. Wissler, H.P. Jennissen, N. Dunker, Chick ex ovo culture and ex ovo CAM assay: how it really works, J Vis Exp (33) (2009).

[32] A. Magnaudeix, J. Usseglio, M. Lasgorceix, F. Lalloue, C. Damia, J. Brie, P. PascaudMathieu, E. Champion, Quantitative analysis of vascular colonisation and angio-conduction in porous silicon-substituted hydroxyapatite with various pore shapes in a chick chorioallantoic membrane (CAM) model, Acta Biomater 38 (2016) 179-89.

[33] T. Huynh, G. Abraham, J. Murray, K. Brockbank, P.-O. Hagen, S. Sullivan, Remodeling of an acellular collagen graft into a physiologically responsive neovessel, Nat Biotech 17(11) (1999) 1083-1086.

[34] F.J. O'Brien, B.A. Harley, M.A. Waller, I.V. Yannas, L.J. Gibson, P.J. Prendergast, The effect of pore size on permeability and cell attachment in collagen scaffolds for tissue engineering, Technol Health Care 15(1) (2007) 3-17.

[35] T. Wu, M. Frydrych, K. O'Kelly, B. Chen, Poly(glycerol sebacate urethane) - Cellulose Nanocomposites with Water-Active Shape-Memory Effects, Biomacromolecules 15 (2014) 2663-2671.

[36] K.A. Faraj, T.H. van Kuppevelt, W.F. Daamen, Construction of collagen scaffolds that mimic the three-dimensional architecture of specific tissues, Tissue Eng 13(10) (2007) 238794.

[37] K.M. Pawelec, A. Husmann, S.M. Best, R.E. Cameron, A design protocol for tailoring ice-templated scaffold structure, J R Soc Interface 11(92) (2014) 20130958.

[38] F.H. Silver, D.L. Christiansen, C.M. Buntin, Mechanical properties of the aorta: a review, Critical reviews in biomedical engineering 17(4) (1989) 323-58.

[39] G. Holzapfel, Biomechanics of Soft Tissue, 2001, pp. 1049-1063. 
[40] H. Azevedo, R. Reis, Understanding the Enzymatic Degradation of Biodegradable Polymers and Strategies to Control Their Degradation Rate, Biodegradable Systems in Tissue Engineering and Regenerative Medicine, CRC Press2004.

[41] W. Cui, X. Li, X. Zhu, G. Yu, S. Zhou, J. Weng, Investigation of drug release and matrix degradation of electrospun poly(DL-lactide) fibers with paracetanol inoculation, Biomacromolecules 7(5) (2006) 1623-9.

[42] S. Sant, D. Iyer, A.K. Gaharwar, A. Patel, A. Khademhosseini, Effect of biodegradation and de novo matrix synthesis on the mechanical properties of valvular interstitial cell-seeded polyglycerol sebacate-polycaprolactone scaffolds, Acta Biomater 9(4) (2013) 5963-73.

[43] S. Roman, A. Mangera, N.I. Osman, A.J. Bullock, C.R. Chapple, S. MacNeil, Developing a tissue engineered repair material for treatment of stress urinary incontinence and pelvic organ prolapse-which cell source?, Neurourol Urodyn 33(5) (2014) 531-7.

[44] C. Frantz, K.M. Stewart, V.M. Weaver, The extracellular matrix at a glance, Journal of Cell Science 123 (2010) 4195-4200.

[45] S. Pal, Design of Artificial Human Joints \& Organs, Springer US2014, pp. 23-40.

[46] X. Xiao, W. Wang, D. Liu, H. Zhang, P. Gao, L. Geng, Y. Yuan, J. Lu, Z. Wang, The promotion of angiogenesis induced by three-dimensional porous beta-tricalcium phosphate scaffold with different interconnection sizes via activation of PI3K/Akt pathways, Sci Rep 5 (2015) 9409.

[47] V.S. Joshi, N.Y. Lei, C.M. Walthers, B. Wu, J.C. Dunn, Macroporosity enhances vascularization of electrospun scaffolds, The Journal of surgical research 183(1) (2013) 18-26. [48] A. Artel, H. Mehdizadeh, Y.C. Chiu, E.M. Brey, A. Cinar, An Agent-Based Model for the Investigation of Neovascularization Within Porous Scaffolds, Tissue Engineering Part A 17(17-18) (2011) 2133-2141. 